\title{
ELECTROPHORESIS
}

\section{Separation of Phenolic Acids and Flavone Natural Antioxidants by Two-dimensional Method Combining Liquid Chromatography and Micellar Electrokinetic Capillary Chromatography}

\begin{tabular}{|r|l|}
\hline Journal: & Electrophoresis \\
\hline Manuscript ID: & elps.200900689.R1 \\
\hline Wiley - Manuscript type: & Research Paper \\
\hline Date Submitted by the \\
Author: & 22-Jan-2010 \\
\hline Complete List of Authors: & $\begin{array}{l}\text { Cesla, Petr; University of Pardubice, Analytical Chemistry } \\
\text { Fischer, Jan; University of Pardubice, Analytical Chemistry } \\
\text { Jandera, Pavel; University of Pardubice, Analytical Chemistry }\end{array}$ \\
\hline Keywords: & $\begin{array}{l}\text { Micellar electrokinetic chromatography, Two-dimensional } \\
\text { separation, Flavones, Phenolic compounds }\end{array}$ \\
\hline
\end{tabular}

\section{S ScholarONE" \\ Manuscript Central}


1

2

3

4

5

6

7

9

\section{Separation of Phenolic Acids and Flavone Natural Antioxidants by Two-Dimensional Method Combining Liquid Chromatography and Micellar Electrokinetic Capillary Chromatography}

Petr Česla, Jan Fischer, Pavel Jandera*

Department of Analytical Chemistry, Faculty of Chemical Technology, University of Pardubice, Studentská 573, CZ-53210 Pardubice, Czech Republic 9 Correspondence:

10 Prof. Pavel Jandera, Department of Analytical Chemistry, Faculty of Chemical Technology, 11 University of Pardubice, Studentská 573, CZ-53210 Pardubice, Czech Republic, E-mail:

12 Pavel.Jandera@upce.cz, Tel: +420 466037 023, Fax: +420 466037068 13

14 Abbreviations:

15 MEKC - Micellar Electrokinetic Chromatography, LC - Liquid Chromatography, SDS -

16 Sodium dodecyl sulphate, 2D - two-dimensional, CE - capillary electrophoresis, CD -

17 cyclodextrins, EOF - electroosmotic flow, C18 - octadecyl, RP - reversed phase, LC-LC two18 dimensional liquid chromatography, LCxLC - comprehensive two-dimensional

19 chromatography, LC-MEKC - two-dimensional combination of liquid chromatography and 20 micellar electrokinetic chromatography. 21

22 Keywords:

23 Flavones, Micellar electrokinetic chromatography, Phenolic compounds, Two-dimensional 24 separations 
26 A two-dimensional method was developed for separation of phenolic acids and

27 flavone compounds combining liquid chromatography with micellar electrokinetic capillary

28 chromatography. The effect of substituted neutral and anionic cyclodextrin additives to the

29 background electrolyte on the quality of MEKC separation was investigated. The best

30 selectivity of the MEKC separation was achieved in $25 \mathrm{mmol} / \mathrm{L}$ borate background buffer at

$31 \mathrm{pH} 9.05$ with the addition of $10 \mathrm{~g} / \mathrm{L}$ SDS and $1.85 \mathrm{~g} / \mathrm{L}$ heptakis-6-O-sulfo- $\beta$-cyclodextrin.

32 These conditions were used in the second dimension of two-dimensional LC-MEKC

Deleted: 35

33 separation in combination with a (poly)ethylene glycol (PEG) column in the first dimension,

Deleted: $\mathrm{mmol}$

34 providing the best orthogonality (the lowest degree of correlation between the selectivity of

35 separation) in the two dimensions. A CE autosampler was employed as the interface between

36 LC and MEKC steps based on automated fraction collection before the re-analysis of the

37 collected LC fractions in the second, MEKC dimension. The 2-D method under optimized

38 conditions was applied for the separation of natural antioxidants in the samples of green tea. 


\section{ELECTROPHORESIS} 1

2

\section{$39 \quad 1$ Introduction}

In recent years, the use of natural occurring compounds, including polyphenolic and

41 flavone compounds, in pharmaceuticals, food supplements and cosmetics was becoming more

42 and more popular. These compounds occur as secondary plant metabolites involved in the

43 production of yellow or red/blue pigmentation or protection of flowers from attack by

44 microbes and insects and show important anti-allergic, anti-inflammatory, anti-microbial and

45 anti-cancer activity [1]. The flavones and related natural antioxidants differ by the degree of

46 hydroxylation, methylation, number of double bonds and, in case of glycosides, by the type

47 and position of sugar moieties [2].

$48 \quad$ Liquid chromatography with different detection modes is frequently used for the

49 analysis and determination of flavones and related compounds [3,4]. Other chromatographic

50 methods - gas chromatography and thin-layer chromatography - are less commonly used for

51 separation of these polar non-volatile compounds $[4,5]$.

52 Capillary electrophoresis (CE) and micellar electrokinetic chromatography (MEKC)

53 techniques have also been used for separation and determination of flavones and phenolic

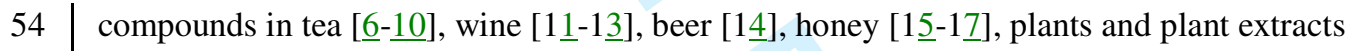

55 [1ㅇ-22]. The MEKC separations of flavone compounds are usually carried out using borate

56 background electrolyte at $\mathrm{pH}>7$, with the addition of sodium dodecyl sulphate micellar

57 reagent $[1 \underline{1}, 1 \underline{2}, 1 \underline{4}, 1 \underline{1}, 1 \underline{8}-22]$. Capillary zone electrophoresis has been used for separation of

58 quercetin $[1 \underline{3}, 2 \underline{2}]$ and other flavones $[1 \underline{6}, 1 \underline{7}]$. The applications of various separation

59 techniques for the separation of polyphenolic and flavone natural antioxidants has been

60 covered in several review articles $[\underline{4}, \underline{5}, 2 \underline{3}, 2 \underline{4}]$.

61 For the separation of complex sample mixtures, two-dimensional separation methods

62 considerably increase the numbers of resolved components due to increased peak capacity in 63 comparison to one-dimensional separations. Recently, 2-D liquid chromatographic_LC-LC) 64 methods for separation of flavones in food, beverages and plant extracts have been developed $65 \mid$ [25-27]. In most applications, two reversed-phase systems with different types of stationary 66 phases are combined in the first and in the second dimension. Natural compounds in the 67 extracts of umbelliferae herbs were separated using gradients of acetonitrile in water on a 68 bonded CN column in the first dimension and of methanol in water on a monolithic $\mathrm{C} 18$ 69 column in the second dimension [28]. Gradient elution provides significant improvement in 70 peak capacity with respect to isocratic conditions. Natural antioxidants were analyzed using 71 simultaneous gradients of acetonitrile in ammonium acetate buffer on a polyethylene glycol or 
72 on a phenyl column in the first dimension and on a C18 column in the second dimension [29].

73 Acidic compounds were separated using a cation-exchange column in the first dimension and

74 a C18 column in the second dimension with a gradient of acetonitrile in acetate buffer [30].

75 Recently, porous-shell fused-core $\mathrm{C} 18$ columns were combined in the second dimension with

76 a microbore column packed with phenyl-silica [31] or with PEG-silica [32] particles in the

77 first dimension for separation of phenolic antioxidants in wine, beverages and other food

78 samples in two-dimensional reversed-phase liquid chromatography.

The best improvement in the number of separated compounds, i.e. the highest increase

in the peak capacity with respect to single-dimension separations is achieved in highly orthogonal two-dimensional systems with non-correlated selectivities in the first and in the second dimension. Two reversed-phase systems are easy to connect on-line, but show more or less correlated separation selectivities and consequently lower than maximum peak capacity can be achieved in practice. On the other hand, combinations of reversed-phase and ionexchange systems are not very suitable for two-dimensional separations of non-ionic compounds, for which ion-exchange columns usually show low retention and separation selectivity. Finally, on-line two-dimensional combinations of reversed-phase and normalphase (adsorption) systems show high degree of orthogonality, but poor compatibility of aqueous-organic RP mobile phases with purely organic solvents used as the mobile phase in normal-phase chromatography. Therefore, combinations of HPLC in one dimension with electromigration separation systems in the other one offer attractive possibilities of highly orthogonal separations, complementary to LC-LC two-dimensional systems. Moreover, electromigration methods are generally like to provide narrow peaks and hence high peak capacity.

Two-dimensional capillary electrophoresis has been applied to separation of proteins [33,34]. 2D combinations of liquid chromatography and capillary electrophoresis offer possibility for increasing the peak capacity for separation of multi-component samples containing ionic compounds. The LC-CE methods have been applied mainly in the analysis of peptides in protein digests and of proteins in various biological samples [31,35-44]. On-line connection of RPLC to capillary zone electrophoresis (CZE) has been introduced by Bushey 101 and Jorgenson [35] and further applied by Jorgenson's group [31,36,37]. Off-line connections 102 of LC and CE have been described by several research groups $[38,39,45]$. The off-line 103 approach is slower than the on-line 2D methods, as it involves the collection of fractions from 104 the first dimension and then the analysis of isolated fractions in the second dimension. On the 105 other hand, it is simple to perform, the volume or the number of the collected fractions is not

\begin{tabular}{l} 
Deleted: The c \\
Deleted: in a 2-D setup \\
Deleted: s another \\
Deleted: studied \\
Deleted: et \\
\hline
\end{tabular}


106 that strictly limited and does not impose restrictions on the dimension of HPLC column in the

107 first dimension. On-line (comprehensive) methods analyze the whole applied amount of

108 sample, offer better automation possibilities and higher sample throughput, however they

109 require special instrument modification, micro- or capillary HPLC columns that can

110 efficiently handle only limited sample volumes and put severe time limitations on the second-

111 dimension separation, which must be accomplished in collection time of the next HPLC

112 fraction from the first dimension.

113 Applications of 2D LC-CE for the analysis of naturally occurring compounds are less

114 common. Garcia-Villalba et al. used HPLC-CE for the analysis of extra-virgin olive oil 115 samples [45]. Selected fractions containing phenolic compounds were isolated for 116 quantification and in vitro studies of anti-carcinogenic capacity. Like ion-exchange liquid 117 chromatography, capillary electrophoresis is not suitable for separations of non-ionic 118 compounds, which can be better separated by micellar electrokinetic chromatography, usually 119 in buffers containing sodium dodecylsulphate (SDS). Zhang et al. [46] employed 120 comprehensive 2-D HPLC-MEKC for the separation of natural compounds in traditional 121 Chinese medicines. The HPLC instrument was connected on-line to the CE system through 122 interface based on effluent stacking-injection of fractions collected from a micro-LC column 123 in a $0.25 \mu 1$ chamber during $50-60 \mathrm{~s}$, which was the time for the second-dimension MEKC 124 analysis.

125 In the present work, the effects of the addition of substituted cyclodextrins to the 126 background electrolyte on the separation selectivity of phenolic acids and flavone related 127 compounds in MEKC were investigated. A 2-D method combining liquid chromatography 128 with MEKC using automated off-line coupling with CE autosampler as the fraction collector 129 interface was developed, to avoid time limitations in the second, MEKC dimension and to 130 allow using a previously optimized HPLC separation on a polyethylene glycol (PEG) column, 131 whose dimensions are not on-line compatible with the MEKC separation in the second 132 dimension $[29,47,48]$. The main objective was to investigate possible improvement of the 133 overall performance of the LC-MEKC method with earlier reported LCxLC 2D separations of 134 phenolic and flavone natural antioxidants [32,49]. The HPLC-MEKC 2-D method was 135 applied for the analysis of green tea samples. 
2 Materials and methods

138

\subsection{Materials and reagents}

A fused silica capillary with extended $125 \mu \mathrm{m}$ light path cell $(25 \mu \mathrm{m}$ I.D., $48 \mathrm{~cm}$ total length, $40 \mathrm{~cm}$ to the detector) was obtained from Agilent (Palo Alto, CA, USA). The

Discovery HS PEG, $5 \mu \mathrm{m}, 50 \mathrm{~mm}$ x $2.1 \mathrm{~mm}$ i.d. column was obtained from Supelco (Bellafonte, PA, USA).

The standards of flavone related compounds and phenolic acids (Figure 1) were obtained from Fluka (Buchs, Switzerland) and Sigma-Aldrich (St. Louis, MO, USA).

Ammonium acetate, boric acid, sodium tetraborate, sodium dodecyl sulphate and substituted cyclodextrins, methyl- $\beta$-cyclodextrin, heptakis(2,6-di-O-methyl)- $\beta$-cyclodextrin, heptakis(2,3,6-tri-O-methyl)- $\beta$-cyclodextrin), and heptakis(6-O-sulfo)- $\beta$-cyclodextrin, were obtained from Fluka (Buchs, Switzerland), acetonitrile was from Sigma-Aldrich (St. Louis, MO, USA), methanol from Merck (Darmstadt, Germany) and formic acid from Lachema (Brno, Czech Republic).

The extract of Jasmine Green Tea, (Twining \& Company Ltd., London, England) was prepared by keeping the tea bag in $100 \mathrm{~mL}$ of $95^{\circ} \mathrm{C}$ hot water for 3 minutes and cooling to the laboratory temperature. Before injection, the extract was filtrated using Millipore $0.45 \mu \mathrm{m}$ syringe filter (Bedford, MA, USA).

\subsection{Equipment}

All MEKC experiments were carried out using Agilent ${ }^{3 \mathrm{D}} \mathrm{CE}$ (Agilent, Palo Alto, CA, USA) instrument at $20 \mathrm{kV}$. pH of the background electrolyte solutions was measured using an Orion 3 Start pH meter (Thermo Scientific, Waltham, MA, USA). Water was purified on an Ultra Clear UV apparatus (SG, Hamburg, Germany). The LC step of the 2-D method was carried out using an Agilent 1200 series Rapid Resolution liquid chromatograph in the first dimension The outlet of the LC column was connected through a switching valve with the $\mathrm{CE}$ autosampler for automated collection of the fractions from first dimension. Figure 2 shows the experimental setup used for the 2D LC-MEKC setup. 


\section{$166 \quad 2.3$ Methods}

167 The LC separations were carried out on a Discovery HS PEG column at $40^{\circ} \mathrm{C}$ using

168 gradient elution with $10 \mathrm{mmol} / \mathrm{L}$ ammonium acetate in water $(\mathrm{pH}=3.0$ adjusted by the

169 addition of formic acid) as the solvent $\mathrm{A}$ and acetonitrile as the solvent $\mathrm{B}$. The mobile phase

170 gradient program was from $1 \%$ to $30 \% \mathrm{~B}$ in $15 \mathrm{~min}$ at $0.4 \mathrm{~mL} / \mathrm{min}$. After the end of each $2-\mathrm{D}$

171 run, the column was equilibrated with the initial gradient mobile phase for $10 \mathrm{~min}$. The

172 injection sample volume was $5 \mu \mathrm{L}$.

173 The detection wavelengths of the CE instruments were set to 220, 254 280 and 350

Deleted: and

$174 \mathrm{~nm}$. All electropherograms were extracted at wavelength $280 \mathrm{~nm}$ being the most general for

175 the different classes of studied compounds. The capillary temperature was kept at $25^{\circ} \mathrm{C}$.

Deleted: ;

176 Samples were injected by applying overpressure of $50 \mathrm{mBar}$ on the inlet sample vial for $10 \mathrm{~s}$

177 in single CE analyses. New capillaries were preconditioned by rinsing subsequently with 0.5

$178 \mathrm{~mol} / \mathrm{L}$ sodium hydroxide for $10 \mathrm{~min}$, with water for the next $10 \mathrm{~min}$ and finally with the

179 background electrolyte for $10 \mathrm{~min}$. Further, the capillaries were rinsed prior to every injection

180 for $1 \mathrm{~min}$ with the background electrolyte. In the LC-MEKC 2D experiments, $25 \mathrm{mmol} / \mathrm{L}$

181 borate buffer $\mathrm{pH} 9.05$ with addition of $10 \mathrm{~g} / \mathrm{L} \mathrm{SDS}$ and $1.85 \mathrm{~g} / \mathrm{L}$ heptakis(6-O-sulfo)- $\beta$ -

182 cyclodextrin was used as the background electrolyte in the second, MEKC dimension. The

183 background electrolytes and mobile phases were filtered using a Millipore (Bedford, MA,

184 USA) $0.45 \mu \mathrm{m}$ filter and degassed by ultrasonication before use.

In the two-dimensional setup, an Agilent ${ }^{3 \mathrm{D}} \mathrm{CE}$ autosampler was used as the interface

186 between the LC and the MEKC separation systems (Figure 2). The outlet of the LC column

187 was connected to the autosampler via a six-port switching valve, which was programmed to

188 collect the fractions of the effluent from the LC column during the analysis in the first

189 dimension (Figure 2A) into the vials equipped with $250 \mu \mathrm{L}$ glass inserts. The $\mathrm{CE}$ autosampler

190 was rotated each $15 \mathrm{~s}$, thus the volume of the fractions was $100 \mu \mathrm{L}$. In total, $421^{\text {st }}$ dimension

191 fractions containing analytes were collected during the gradient elution, from 0.5 min to

$19211 \mathrm{~min}$, for the analysis in the MEKC $2^{\text {nd }} \mathrm{D}$ system.

193 The fractions collected from the LC dimension were stored in the autosampler vials

194 until the LC analysis run has been finished. After the end of the LC step, the valve was

195 switched into the second position and the effluent from the first dimension was redirected to

196 the waste while the LC column was re-equilibrated with the mobile phase used at the start of

197 the gradient. Meanwhile, the collected fractions were subsequently analyzed in the MEKC

198 second dimension (Figure 2B). 
199 The UV detector signal of the CE instrument was processed using the export function 200 of the CE Chemstation software. The exported ASCII data were converted into a matrix with 201 the rows corresponding to the fraction cycle periods. The $2 \mathrm{D}$ chromatograms were plotted as 202 the contour plots with the first dimension times on the $\mathrm{x}$-axis and the second dimension times 203 on the $y$-axis coordinates, respectively, using proprietary software developed for the 204 evaluation of 2D LCxLC chromatograms [32]. The identification of the sample compounds 205 was based on the comparison of the LC elution times and the CE migration times in the 206 individual dimensions and the signal ratio at the four pre-set wavelengths $(220,254,280$ and Deleted: three $207 \underline{350 \mathrm{~nm}) .}$

\section{Results and discussion}

\subsection{Optimization of the MEKC separation of phenolic and flavone compounds.}

In continuation of our earlier studies of the applications of two-dimensional LCxLC

212 methods for separation of flavones and phenolic acids [26,29,32,47], we investigated

213 possibilities of using electromigration separation instead of LC separation in the second

214 dimension of a two-dimensional system. Most flavone compounds are not-ionized in

215 background electrolytes commonly used in CZE separations. To obtain successful separation

216 of these compounds, we used MEKC with sodium dodecyl sulphate additive (SDS). For this

217 purpose, we first optimized the MEKC step for best separation of 25 selected representative

218 standard compounds (Fig. 1). Based on the previously published results [14], we used 25

$219 \mathrm{mmol} / \mathrm{L}$ borate background electrolyte with $\mathrm{pH}$ adjusted to 9.05 to obtain appropriate

220 electroosmotic flow velocity. On the basis of the experimental migration times, $t_{m i}$, we

221 calculated the MEKC retention factors, $k_{i}$, of sample compounds using the well-known Eq.

222 (1):

$$
k=\frac{t_{m, i}-t_{E O F}}{t_{E O F}\left(1-\frac{t_{m, i}}{t_{M I C}}\right)}
$$

Here, $t_{E O F}$ is the migration time of the electroosmotic flow, measured as the migration

226 III dye as the marker compound, which is completely retained in the SDS micellar pseudo-

227 stationary phase. All sample compounds appear between $t_{E O F}$ and $t_{m i c}$. Table 1 shows the

228 experimental $t_{m \underline{i}}$ of the standard compounds in various working electrolytes tested.

229 The mobility and hence the migration times and the retention factors of flavones and

230 phenolic compounds in MEKC depend on their structures. Generally, the mobility increases 
1

231 with increasing number of -OH groups (myricetin, $6<$ quercetin, morin, $5<$ apigenin, $3<7$ -

232 hydroxyflavone, 1). Further, catechins with five hydroxy groups ((+)-catechin and (-)-

233 epicatechin) migrate faster than quercetin with the same number and position of hydroxy-

234 groups, but flavone structure (Fig. 3A). Retention of flavonoid glycosides is affected by the

235 position of glycosylation: hesperidin and naringin (glycosylated at the position 7) elute later

236 than corresponding aglycones hesperetin and naringenin, but rutin (glycosylated at the

237 position 3) migrates faster than quercetin. First, we investigated the effect of the SDS on the

238 separation in the concentration range $4.3-20.2 \mathrm{~g} / \mathrm{L}$. Generally, the migration times and the

239 resolution increase at higher concentrations of the SDS micelles in the background

240 electrolyte. This effect is stronger for the compounds with lower migration velocities. The

241 electrolytes with $10 \mathrm{~g} / \mathrm{L}$ SDS provided the best compromise between the resolution of the

242 standards and the time of analysis, hence we used this concentration throughout this work

243 with various electrolytes (Fig. 3A).

244 Many flavone and phenolic acid standards could be separated by MEKC with $10 \mathrm{~g} / \mathrm{L}$ SDS in

245 the background electrolyte, however some critical pairs could not be resolved in this system

246 and some standards were only partially separated (e.g., hesperetin/4-hydroxyphenylacetic

247 acid, syringic acid/myricetin, chlorogenic acid/vanilic acid/salicylic acid,

248 quercetin/morin/hesperidin, p-hydroxybenzoic acid/apigenin, 7-hydroxyflavone/biochanin A)

249 . To improve the resolution, we tested the effects of the organic solvents and various

250 substituted cyclodextrin additives (CD) to the background electrolyte. The addition of

251 methanol or acetonitrile up to $20 \%$ (v/v) did not improve the separation, but only increased

252 the time of analysis. The increase in the separation time was due to the effect of the organic

253 solvent on decreased experimental EOF mobility, which was $36.0 \times 10^{-8} \mathrm{~m}^{2} \mathrm{~V}^{-1} \mathrm{~s}^{-1}$, in purely aqueous electrolyte without an organic solvent additive; $23.8 \times 10^{-8} \mathrm{~m}^{2} \mathrm{~V}^{-1} \mathrm{~s}^{-1}$ in the electrolyte with $15 \%$ methanol and $27.9 \times 10^{-8} \mathrm{~m}^{2} \mathrm{~V}^{-1} \mathrm{~s}^{-1}$. in the electrolyte with $15 \%$ acetonitrile.

In the background electrolytes with cyclodextrins, the partitioning equilibrium in MEKC is affected by the formation of complexes of samples with cyclodextrins in the aqueous phase, which compete for the analytes with the micellar pseudostationary phase. We compared three non-charged cyclodextrins (methyl- $\beta$-cyclodextrin, heptakis(2,6-di-O-

260 methyl)- $\beta$-cyclodextrin, heptakis(2,3,6-tri-O-methyl)- $\beta$-cyclodextrin) and negatively charged 261 heptakis(6-O-sulfo)- $\beta$-cyclodextrin) additives to the background electrolyte. The neutral CDs 262 migrate along the capillary towards the detector (cathode) at the electroosmotic flow (EOF) 263 migration velocity, whereas the negatively charged CD moves in the same direction, but at 
264 different migration velocity as the SDS micelles, i.e., against the direction of EOF. The

265 resulting migration velocities are further contributed to by the own electrophoretic mobilities

266 of phenolic compounds, which are more or less ionized in the running buffers at $\mathrm{pH}=9$. This

267 applies mainly to phenolic acids, but even other compounds may be present in the form of

268 anions. Taking into account all these complex equilibria, it is not possible to predict a-priori

269 general effects of the CD additives on the migration times, separation selectivity and

270 resolution, which strongly depend on the sample structures.

271 Table 1 shows the retention factors of the test standards in running buffers with 1.3 -

$2727.2 \mathrm{~g} / \mathrm{L}$ cyclodextrins and $10 \mathrm{~g} / \mathrm{L}$ SDS. The values and even the order of migration times of

273 flavones and phenolic acids depend significantly on the type and concentration of

274 cyclodextrin in the running buffer. Cyclodextrin additives affect also the bandwidths and the

275 separation efficiency characterized by the number of theoretical plates per meter, $N$ (Table 1).

276 The methyl- $\beta$-cyclodextrin additive decreases the plate number by $20-25 \%$ with respect to the

277 buffer without the CD additive. The other CD additives moderately decrease the separation

278 efficiency only at the concentrations of $4 \mathrm{~g} / \mathrm{L}$ or more.

279 To compare the performance of various running buffers, we selected the "critical

\begin{tabular}{|l|}
\hline Deleted: 5 \\
Deleted: $\mathrm{mmol}$ \\
Deleted: $35 \mathrm{mmol}$ \\
\hline
\end{tabular}

280 pairs" of standard phenolic and flavone compounds with adjacent peaks, $i$ and $j$, which are

281 most difficult to resolve in various MEKC systems. For these "critical pairs" we determined

282 the separation selectivity, $\alpha_{i, j}$, defined as the ratio of the corresponding retention factors, $k_{i}$ (of

283 earlier migrating compound $i$ ) and $k_{j}$ (of later migrating compound $j$ ), respectively:

$$
\alpha_{i, j}=\frac{k_{j}}{k_{i}}=\frac{t_{m, j}-t_{E O F}}{t_{m, i}-t_{E O F}} \cdot \frac{1-\frac{t_{m, i}}{t_{M I C}}}{1-\frac{t_{m, j}}{t_{M I C}}}
$$

286 The separation selectivity $\alpha_{i, j}=1$ means that the analytes $i$ and $j$ co-elute in a single peak; the

287 higher is $\alpha_{i, j}$, the better is the separation selectivity and the resolution of analytes.

288 The separation selectivity for "critical pairs" of flavones and phenolic acids

Deleted: standards of 289 significantly depends on the type of cyclodextrin (Table 2). The number of "critical pairs"

290 with resolution $R_{S, i, j}<1$ significantly decreases in working buffers containing CD additives (

29110 in the buffer without CD, 9 in the buffer with methyl- $\beta$-cyclodextrin, 7 in the buffer with

292 heptakis(2,6-di-O-methyl)- $\beta$-cyclodextrin and 4 in the buffer with heptakis(2,3,6-tri-O-

293 methyl)- $\beta$-cyclodextrin). The improvement of separation selectivity and resolution is even 
294 better in the buffers containing negatively charged heptakis(6-O-sulfo)- $\beta$-cyclodextrin), where

295 there are only three "critical pairs" with $R_{S, i, j}<1$. The concentration of the CDs also strongly

296 affects the selectivity of separation and the resolution. It should be noted that the change in

297 the type and concentration of the CD additive to the running buffer may cause change in the

298 order of migration times of "critical pairs". The reversed migration order is marked by asterisk

299 in Table 2.

Fig. 4 shows the plots of resolution of some critical pairs of flavones and phenolic 301 acids versus the concentration of heptakis(6-O-sulfo)- $\beta$-cyclodextrin in background 302 electrolyte. Most significant improvement in resolution was achieved in the background 303 electrolyte with $1.85 \mathrm{~g} / \mathrm{L}$ anionic heptakis(6-O-sulfo)- $\beta$-cyclodextrin. 304 The separation of 25 test compounds in this background electrolyte shown in Fig. 3B 305 is only slightly longer than in the buffer without CD (Fig. 3A), but the resolution of the pairs 306 of compounds $1 / 2,11 / 21,6 / 13$ improves considerably and there are 20 resolved peaks in the 307 sample in comparison to 18 in the buffer without $\mathrm{CD}$. The addition of $1.85 \mathrm{~g} / \mathrm{L}$ heptakis(6-O308 sulfo)- $\beta$-cyclodextrin does not affect the efficiency (the number of theoretical plates, Table 1). 309 Hence, this optimized running buffer composition was applied for the separation of flavones 310 and phenolic acids in the two-dimensional LC-MEKC system.

\subsection{Correlations between the LC and MEKC methods}

313 The best improvement of resolution and peak capacity in 2D systems is achieved in 314 so-called "orthogonal" systems, where the separation principles in both dimensions are 315 completely different. The degree of orthogonality of a two-dimensional separation system can 316 be described by the correlation coefficient of the retention (migration) times, or of the 317 retention factors in the two dimensions [49]. We compared the retention times of flavones and 318 phenolic acids on four HPLC columns with different stationary phases and dimensions with 319 the MEKC migration times in the running buffer with $1.85 \mathrm{~g} / \mathrm{L}$ heptakis(6-O-sulfo)- $\beta$ -

320 cyclodextrin (Table 3). Other MEKC separation systems showed similar correlations with the 321 HPLC separations and are not shown here. There are generally low correlations between the 322 MEKC and HPLC characteristics. The lowest correlations of the migration times for both 323 flavone compounds and phenolic acids was observed for the column 2 (Discovery HS PEG), 324 with a polyethyleneglycol bonded stationary phase, higher for the column 3 (Novapak 
327 selectivity of non-charged compounds in the MEKC systems with SDS micelles in the

328 background electrolyte and the non-polar stationary phases in reversed-phase liquid

329 chromatography.

330 This trend in system correlations agrees with our previously published work[48] -

331 [50], where the combinations of a PEG column with a C18 column provide highly different

332 chromatographic selectivity and high degree of orthogonality in comprehensive two-

333 dimensional LCxLC. The correlation coefficients between the retention data of flavone and

334 phenolic acid standards on a PEG column and on various C18 columns, including monolithic,

335 fully porous particle and superficially porous solid core particles, $R^{2}=0.07-0.43$, higher

336 than in the LC-MEKC two-dimensional setup described in the present work (0.049, Table 3),

337 which therefore shows higher orthogonality. Moreover, a lower concentration of acetonitrile

338 in the mobile phase used for the separation of flavones and phenolic acids on the PEG column

339 in comparison to the $\mathrm{C} 18$ column is beneficial for the MEKC separation in the second

340 dimension, where the injection of sample dissolved in mobile phase with high concentration

341 of organic solvent can decrease the concentration of micelles and impair the resolution of

342 sample compounds.

343

344

\subsection{Two-dimensional LC-MEKC separations}

To match the column dimensions with the separation capillary in the MEKC system 345 and to minimize the dilution of the transferred fractions, a narrow-bore polyethyleneglycol column was selected for the first dimension in the LC-MEKC separations (Discovery HS

348 PEG, 50x2.1 mm i.d., $5 \mu \mathrm{m}$ particles), with a gradient of acetonitrile in aqueous ammonium

349 acetate buffer. Fig. 5 shows the two-dimensional separation of the standard compounds as a 350 contour plot) with the HPLC elution times on the $\mathrm{X}$-axis and the MEKC migration times on 351 the Y-axis in the optimized 2D off-line separation system. All 25 standards are resolved and 352 there are some spots of minor impurities in the two-dimensional retention plane. The 353 estimated maximum theoretical peak capacity, based on the average experimental bandwidths 354 is approximately 450 in the present automated off-line 2D LC-MEKC system, in comparison 355 to 30 in the MEKC and 20 in the HPLC one-dimensional systems. The overall time necessary 356 for the subsequent MEKC analysis of all HPLC fractions is long, 10.5 hours, but the analysis 357 can run unattended overnight. In the recently reported comprehensive LCxLC 2D method 358 with a PEG column in the first dimension and a porous-shell fused core Ascentis C18 column 359 in the second dimension [32], we could completely resolve 24 compounds of 27 phenolic 360 acids and flavone standards in 30 min total separation time. However, the second dimension 
peak capacity was only 12 and the total two-dimension peak capacity was cca 280 , slightly more than half of the peak capacity in the present work. We are presently working on the reduction of the second dimension MEKC separation time. Fig. 6 shows an example of practical applications of the present two-dimensional LC-MEKC system for the separation of

365 a sample of green tea extract.

\section{Concluding remarks}

MEKC separation of 25 flavone related compounds and phenolic acid standards was achieved in 15 min using an optimized MEKC system employing the background electrolyte 370 containing $25 \mathrm{mmol} / \mathrm{L}$ borate buffer $(\mathrm{pH} 9.05)$ with the addition of $10 \mathrm{~g} / \mathrm{L}$ SDS and $1.85 \mathrm{~g} / \mathrm{L}$ 371 heptakis(6-O-sulfo)- $\beta$-cyclodextrin. The presence of anionic cyclodextrin additive allows 372 improving the resolution of the MEKC method. An automated off-line two-dimensional

\begin{tabular}{|l|}
\hline Deleted: 35 \\
\hline Deleted: $\mathrm{mmol}$ \\
\hline Deleted: $\mathrm{mmol}$ \\
\hline Deleted:
\end{tabular}
373 separation system was developed coupling a HPLC gradient separation on a bonded 374 polyethylene glycol column in the first dimension and a MEKC separation in a borate buffer 375 with SDS and cyclodextrin additives. comprehensive on-line real-time LC-MEKC 2D system. The off-line system does not require

The experimental setup developed in this work has several advantages over the that the analysis of the collected fraction in the second dimension should be accomplished in the time of collection of the next fraction. Less stringent limitations of the second-dimension 380 separation time considerably increase the available second-dimension peak capacity and the 381 number of peaks that can be resolved during a single analysis run, of course at the cost of a 382 longer total analysis time. Further, using an external fraction collector to store the fractions of 383 the HPLC column effluent in vials, matching the lengths and inner diameters of the HPLC 384 column and the MEKC capillary and the flow rates in both separation systems is not that 385 critical as in the comprehensive setup. The whole 2D system is closed and fully automated, so 386 that there is less risk of loosing some sample during the manipulation with the collected 387 fractions, which improves the reliability of the system. Last but not least, the analysis of the 388 individual fractions in the second dimension can be repeated and (or) the on-line pre389 concentration step of the sample in the capillary before the MEKC analysis can be employed 390 to improve the sensitivity and the detection limits. $391 \quad$ Further research is in progress to investigate the possibilities of reducing the overall 392 analysis time in a high peak capacity two-dimensional LC/MEKC system. 


\section{Acknowledgements}

395 This work was supported by the Ministry of Education, Youth and Sports of the Czech

396 Republic, project No. MSM0021627502 and by the Czech Science Foundation, projects Nos.

397 203/09/P199 and 203/07/0641.

398

\section{References}

400 1. Di Carlo, G., Mascolo, N., Izzo, A. A., Capasso, F., Life Sciences 1999, 65, 337-353.

$401 \quad 2 . \quad$ Heim, K. E., Tagliaferro, A. R., Bobilya, D. J., J. Nutr. Biochem. 2002, 13, 572-584.

Formatted: Italian (Italy)

402 3. Molnar-Perl, I., Fuzfai, Z., J. Chromatogr. A 2005, 1073, 201-227.

403 4. de Rijke, E., Out, P., Niessen, W. M. A., Ariese, F., Gooijer, C., Brinkman, U. A. Th.,

404 J. Chromatogr. A 2006, 1112, 31-63.

$405 \quad$ 5. Stalikas, C. D., J. Sep. Sci. 2007, 30, 3268-3295.

406 6. Nelson, B. C., Thomas, J. B., Wise, S. A., Dalluge, J. J., J. Microcol. Sep. 1998, 10,

407 671-679.

408 7. Barroso, M. B., Van de Werken, G., HRC J. High Resolut. Chromatogr. 1999, 22,

409 225-230.

410 8. Bonoli, M., Pelillo, M., Toschi, T. G., Lercker, G., Food Chemistry 2003, 81, 631-

411638.

412 9. Aucamp, J. P., Hara, Y., Apostolides, Z., J. Chromatogr. A 2000, 876, 235-242.

413 10. Horie, H., Kohata, K., J. Chromatogr. A 1998, 802, 219-223.

414 11. Sun, Y., Fang, N., Chen, D. D. Y., Donkor, K. K., Food Chemistry 2008, 106, $415-$

415420 .

416 12. Rodriguez.Delgado, M. A., Perez, M. L., Corbella, R., Gonzales, G., Montelongo, F. J.

417 G., J. Chromatogr. A 2000, 871, 427-438.

418 13. Wang, S. P., Huang, K. J., J. Chromatogr. A 2004, 1032, 273-279.

419 14. Cortacero-Ramirez, S., Segura-Carretero, A., Cruces-Blanco, C., de Castro, M. H. B.,

$420 \quad$ Fernandez-Gutierez, A., Electrophoresis 2004, 25, 1867-1871.

421 15. Ferreres, F., Blazquez, M. A., Gil, M. L., Tomas-Barberan, F. A., J. Chromatogr. A

$4221994,669,268-274$.

423 16. Andrade, P., Ferreres, F., Gil, M. L., Tomas-Barberan, F. A., Food Chem. 1997, 60,

$42479-84$

425 17. Fu, S. H., Yang, M. H., Wen, H. M., Chern, J. C., J. Food Drug Anal. 2005, 13, 43-50. 
426 18. Dadáková, E., Procházková, E., Křížek, M., Electrophoresis 2001, 22, 1573-1578.

427 19. Pietta, P. G., Mauri, P. L., J. Chromatogr. 1991, 549, 367-373.

428 20. Cheung, H. Y., Lai, W. P., Cheung, M. S., Leung, F. M., Hood, D. J., Fong, W. F., J.

429 Chromatogr. A 2003, 989, 303-310.

430 21. Zhu, J. H., Yu, K., Chen, X. G., Hu, Z. D., J. Chromatogr. A 2007, 1166, 191-200.

431 22. Cao, Y. H., Lou, C. G., Fang, Y. Z., Ye, J. N., J. Chromatogr. A 2002, 943, 153-157.

432 23. Liu, E. H., Qi, L. W., Cao, J., Li, P., Li, C. Y., Peng, Y. B., Molecules 2008, 13, 25214332544 .

434 24. Watanabe, T., Terabe, S., J. Chromatogr. A 2000, 880, 311-322.

435 25. Dugo, P., Kumm, T., Cacciola, F., Dugo, G., Mondello, L., J. Liq. Chromatogr. 436 Related Technol. 2008, 31, 1758-1807.

437 26. Hájek, T., Škeříková, V., Česla, P., Vyňuchalová, K., Jandera, P., J. Sep. Sci. 2008, $438 \quad 31,3309-3328$.

439 27. Dugo, P., Cacciola, F., Herrero, M., Donato, P., Mondello, L., J. Sep. Sci. 2008, 31, 440 3297-3308.

441 28. $\quad$ Hu, L., Chen, X., Kong, L., Su, X., Ye, M., Zou, H., J. Chromatogr. A 2005, 1092, 442 191-198.

443 29. Cacciola, F., Jandera, P., Hajdú, Z., Česla, P., Mondello, L., J. Chromatogr. A 2007, 444 1149, 73-87.

30. Pól, J., Hohnová, B., Jussila, M., Hyötyläinen, T., J. Chromatogr. A 2006, 1130, 6471.

31. Larmann, J. P., Lemmo, A. V., Moore, A. W., Jorgenson, J. W., Electrophoresis 1993, $\underline{14,439-447 .}$

32. Česla, P., Hájek, T., Jandera, P., J. Chromatogr. A 2009, 1216, 3443-3457.

33. Michels, D. A., Hu, S., Schoenherr, R. M., Eggertson, M. J., Dovichi, N. J., Moll. Cell. Proteomics 2002, 1, 69-74.

34. Kraly, J. R., Jones, M. R., Gomez, D. G., Dickerson, J. A., Harwood, M. M., Eggertson, M., Paulson, T. G., Sanchez, C. A., Odze, R., Feng, Z., Reid, B. J., Dovichi, N. J., Anal. Chem. 2006, 78, 5977-5986.

35. Bushy, M. M., Jorgenson, J. W., Anal. Chem. 1990, 62, 978-984.

36. Moore, A. W., Jorgenson, J. W., Anal. Chem. 1995, 67, 3456-3463.

37. Lewis, K. C., Opiteck, G. J., Jorgenson, J. W., Sheeley, D. M., J. Am. Soc. Mass Spectrom. 1997, 8, 495-500. 
459 38. Issaq, H. J., Chan, K. C., Janini, G. M., Muschik, G. M., Electrophoresis 1999, 20,

460 1533-1537.

461 39. Mikulikova, K., Eckhardt, A., Miksik, I., J. Sep. Sci. 2006, 29, 1126-1131.

462 40. Yang, X., Zhang, X., Li, A., Zhu, S., Huang, Y., Electrophoresis 2003, 24, 1451-1457.

463 41. Michels, D. A., Hu, S., Dambrowitz, K. A., Eggertson, M. J., Lauterbach, K., Dovichi, N. J., Electrophoresis 2004, 25, 3098-3105.

42. Janini, G. M., Chan, K. C., Conrads, T. P., Issaq, H. J., Veenstra, T. D., Electrophoresis 2004, 25, 1973-1980.

43. Evans, Ch. R., Jorgenson, J. W., Anal. Bioanal. Chem. 2004, 378, 1952-1961.

44. Tempels, F. W. A., Wiese, G., Underberg, W. J. M., Somsen, G. W., de Jong, G. J., J. Chromatogr. B 2006, 839, 30-35.

45. Garcia-Villalba, R., Carrasco-Pancorbo, A., Vazquez-Martin, A., Oliveras-Ferraros, C., Menendez, J. A., Segura-Carretero, A., Fernandez-Gutierrez, A., Electrophoresis 2009, 30, 2688-2701.

46. Zhang, X., Hu, H., Xu, S., Yang, X., Zhang, J., J. Sep. Sci. 2001, 24, 385-391.

47. Blahová, E., Jandera, P., Cacciola, F., Mondello, L., J. Sep. Sci. 2006, 29, 555-566.

48. Cacciola, F., Jandera, P., Blahová, E., Mondello, L., J. Sep. Sci. 2006, 29, 2500-2513.

49. Jandera, P., Česla, P., Hájek, T., Vohralík, G., Vyňuchalová, K., J. Chromatogr. A 2008, 1189, 207-220.

478 50. Jandera, P., Vyňuchalová, K., Hájek, T., Česla, P., Vohralík, G., J. Chemometrics $479 \quad 2008,22,203-217$. 


\section{ELECTROPHORESIS}

1

2

6

7

8

9

\section{$480 \quad$ Figure captions}

481

\section{Figure 1}

483 Structures of flavone compound and phenolic acid standards.

\section{$485 \quad$ Figure 2}

486 Experimental setup used in the automated off-line LC-MEKC two-dimensional method.

487 LC separation and fraction collecting step (A), MEKC analysis of collected fractions (B). 1 488 HPLC separation_column, 2 - switching valve, 3 - fused silica capillary, $50 \mu \mathrm{m}$ i.d., $200 \mu \mathrm{m}$ 489 o.d., distance approx. $1 \mathrm{~mm}$ between the end of the capillary and the cap of the vial, $4-\mathrm{CE}$ 490 autosampler, vials with $100 \mu \mathrm{L}$ glass insert and with adapted caps with $4 \mathrm{~mm}$ hole, $5-\mathrm{CE}$ 491 separation capillary, 6 - background electrolyte vials, 7 - sample inject vial.

494 MEKC separations of 25 flavones and phenolic acids in background electrolyte containing 10 $495 \mathrm{~g} / \mathrm{L}$ SDS (A) and with addition of $1.85 \mathrm{~g} / \mathrm{L}$ heptakis(6-O-sulfo)- $\beta$-cyclodextrin $(\mathbf{B})$.

\section{Deleted: 35}

Deleted: $\mathrm{mmol}$

Deleted: $\mathrm{mmol}$

Deleted: 35 Deleted: $\mathrm{mmol}$ Deleted: 2 $49925^{\circ} \mathrm{C}$. The numbers of compounds are as in Figure 1.

502 The effect of heptakis(6-O-sulfo)- $\beta$-cyclodextrin concentration, $c_{\mathrm{CD}}$, in background

503 electrolyte on resolution, $R_{\mathrm{s}}$, of some critical pairs of flavones.

504 Capillary, background electrolyte and other separation conditions as in Figure 3, except for 0 $505-5.6 \mathrm{~g} / \mathrm{L}$ of heptakis $(6-\mathrm{O}-\mathrm{sulfo})-\beta$-cyclodextrin, $20 \mathrm{kV}$. The numbers of compounds are as in 506 Figure 1.

507

\section{Figure 5}

509 2-D separation of 25 flavone and phenolic acid standards. The numbers of compounds are as

510 in Figure 1. See text for experimental conditions. 511 $512 \quad$ Figure 6 
513 2-D separation of a green tea sample. The numbers of compounds are as in Figure 1. 
Retention factors, $k$, calculated using Eq. (1), electroosmotic flow time, $t_{E O F}$, migration time of micelles, $t_{M I C}$, and efficiencies of the separation of flavones and

\begin{tabular}{|c|c|c|c|c|c|c|c|c|c|c|c|c|c|}
\hline \multirow{2}{*}{\multicolumn{2}{|c|}{$\begin{array}{l}\text { Compound } \\
\text { Cyclodextrin concentration }[\mathrm{g} / \mathrm{L}]\end{array}$}} & Without CD & \multicolumn{3}{|c|}{ methyl- $\beta-C D$} & \multicolumn{3}{|c|}{ heptakis(6-di-O-methyl)- $\beta$-CD } & \multicolumn{3}{|c|}{ heptakis(6-tri-O-methyl)- $\beta$-CD } & \multicolumn{2}{|c|}{ heptakis(6-O-sulfo)- $\beta$-CD } \\
\hline & & 0 & 1.31 & 3.93 & 6.6 & 1.33 & 4.00 & 6.66 & 1.43 & 4.29 & 7.15 & 1.85 & 5.55 \\
\hline \multicolumn{2}{|c|}{$t_{E O F}[\mathrm{~min}]$} & 4.96 & 5.10 & 5.19 & 5.30 & 5.22 & 5.29 & 5.37 & 5.20 & 5.26 & 5.35 & 5.12 & 5.54 \\
\hline \multicolumn{2}{|c|}{$t_{M I C}[\mathrm{~min}]$} & 15.29 & 15.25 & 15.21 & 15.26 & 16.09 & 16.16 & 16.15 & 15.69 & 15.71 & 15.55 & 18.08 & 20.19 \\
\hline 1 & (-)-Epicatechin & 3.99 & 4.23 & 4.41 & 4.64 & 4.53 & 4.69 & 4.90 & 4.60 & 4.80 & 5.13 & 4.15 & 5.57 \\
\hline 2 & (+)-Catechin & 4.29 & 4.54 & 4.73 & 4.93 & 4.86 & 5.05 & 5.27 & 4.95 & 5.19 & 5.57 & 5.15 & 6.34 \\
\hline 7 & Rutin & 5.30 & 5.80 & 6.10 & 6.44 & 6.22 & 6.51 & 6.76 & 6.39 & 6.70 & 7.14 & 5.76 & 9.00 \\
\hline 10 & Naringenin & 6.22 & 6.70 & 6.88 & 6.98 & 7.29 & 7.57 & 7.47 & 7.32 & 7.16 & 7.68 & 6.35 & 8.77 \\
\hline 11 & Hesperetin & 6.85 & 7.22 & 6.88 & 6.72 & 7.83 & 7.57 & 7.73 & 7.77 & 7.34 & 7.14 & 7.11 & 11.06 \\
\hline 21 & 4-Hydroxyphenylacetic acid & 6.85 & 7.59 & 8.12 & 8.72 & 8.18 & 8.67 & 9.18 & 8.43 & 8.98 & 9.85 & 6.68 & 8.58 \\
\hline 24 & Ferulic acid & 8.02 & 8.64 & 9.22 & 9.94 & 9.33 & 9.86 & 10.46 & 9.58 & 10.22 & 11.22 & 7.76 & 9.60 \\
\hline 20 & Syringic acid & 8.46 & 8.64 & 9.22 & 9.94 & 9.33 & 9.86 & 10.46 & 9.58 & 10.22 & 11.22 & 7.76 & 9.60 \\
\hline 14 & Myricetin & 8.46 & 9.48 & 10.22 & 10.81 & 10.23 & 11.20 & 11.39 & 10.72 & 11.42 & 12.36 & 12.42 & 16.21 \\
\hline 23 & p-Coumaric acid & 9.58 & 10.41 & 12.28 & 12.21 & 11.27 & 13.16 & 12.83 & 11.60 & 12.48 & 14.27 & 9.26 & 12.57 \\
\hline 25 & Chlorogenic acid & 10.43 & 8.64 & 10.22 & 10.81 & 10.23 & 11.20 & 11.39 & 10.58 & 11.26 & 12.36 & 8.06 & 10.39 \\
\hline 19 & Vanilic acid & 10.43 & 10.41 & 12.28 & 13.95 & 12.33 & 13.16 & 14.09 & 12.70 & 13.71 & 15.45 & 9.95 & 12.57 \\
\hline 18 & Salicylic acid & 10.43 & 11.82 & 12.87 & 13.95 & 12.78 & 13.81 & 15.14 & 13.41 & 14.44 & 16.31 & 9.95 & 13.46 \\
\hline 6 & Quercetin & 13.12 & 14.50 & 16.76 & 16.99 & 14.05 & 13.81 & 11.39 & 13.41 & 16.51 & 13.81 & 14.89 & 11.06 \\
\hline 13 & Morin & 13.12 & 17.94 & 17.48 & 16.99 & 22.74 & 23.62 & 25.39 & 22.72 & 24.95 & 29.02 & 15.54 & 16.21 \\
\hline 12 & Hesperidin & 13.12 & 14.50 & 16.42 & 14.59 & 16.72 & 17.16 & 12.83 & 17.47 & 14.44 & 16.31 & 17.79 & 21.50 \\
\hline 17 & p-Hydroxybenzoic acid & 15.95 & 14.50 & 17.48 & 17.73 & 15.81 & 19.11 & 18.84 & 16.39 & 17.85 & 21.48 & 12.06 & 17.07 \\
\hline 5 & Apigenin & 15.95 & 20.33 & 22.07 & 23.22 & 20.66 & 19.11 & 19.48 & 20.72 & 17.85 & 20.42 & 16.15 & 16.21 \\
\hline 4 & 7-Hydroxyflavone & 17.26 & 12.69 & 10.22 & 8.72 & 14.05 & 12.00 & 9.18 & 13.41 & 9.45 & 9.85 & 12.42 & 17.07 \\
\hline 9 & Biochanin A & 17.26 & 17.94 & 16.42 & 12.21 & 20.05 & 20.03 & 19.48 & 20.72 & 24.95 & 29.02 & 16.15 & 27.71 \\
\hline 8 & Naringin & 18.99 & 17.94 & 16.42 & 14.59 & 21.50 & 17.90 & 15.51 & 22.72 & 16.51 & 13.81 & 15.54 & 27.71 \\
\hline 22 & Caffeic acid & 25.57 & 34.18 & 36.19 & 47.57 & 36.82 & 46.92 & 49.55 & 40.02 & 45.81 & 62.57 & 22.03 & 33.08 \\
\hline 15 & Gallic acid & 32.10 & 45.00 & 58.30 & 76.40 & 59.44 & 57.26 & 78.46 & 63.82 & 76.47 & 107.92 & 29.69 & 49.06 \\
\hline 16 & Protocatechuic acid & 52.68 & 77.95 & 106.28 & 179.83 & 96.12 & 113.83 & 180.66 & 112.56 & 160.52 & 499.58 & 39.77 & 78.79 \\
\hline 3 & Flavone & 84.97 & 121.71 & 106.28 & 97.90 & 180.65 & 152.06 & 118.93 & 220.57 & 160.52 & 123.38 & 64.50 & 1408.6 \\
\hline $\begin{array}{l}\mathrm{Av} \\
\text { pla }\end{array}$ & $\begin{array}{l}\text { ge number of theoretical } \\
\text { per meter of capillary }\end{array}$ & 196000 & 153000 & 147000 & 160000 & $\begin{array}{r}190000 \\
\text { Viley-VCI }\end{array}$ & 170000 & 136000 & 202000 & 186000 & 172000 & 191000 & 151000 \\
\hline
\end{tabular}


Table 2

Separation selectivities, $\alpha_{i, j}$, calculated according to the Eq. (2) and resolution, $R s_{i, j}$, of the critical pairs of flavones and phenolic acids in $25 \mathrm{mmol} / \mathrm{L}$ borate background electrolyte $\mathrm{pH} 9.05$ with $10 \mathrm{~g} / \mathrm{L}$ SDS and addition of various cyclodextrins.

\begin{tabular}{|c|c|c|c|c|c|c|c|c|c|c|}
\hline $\begin{array}{l}\text { Critical } \\
\text { pairs } i, j\end{array}$ & \multicolumn{2}{|c|}{ Without CD } & \multicolumn{2}{|c|}{$\begin{array}{l}3.93 \mathrm{~g} / \mathrm{L} \\
\text { methyl- } \beta-\mathrm{CD}\end{array}$} & \multicolumn{2}{|c|}{$\begin{array}{l}4.0 \mathrm{~g} / \mathrm{L} \\
\text { heptakis(6-di-O- } \\
\text { methyl)- } \beta-\mathrm{CD}\end{array}$} & \multicolumn{2}{|c|}{$\begin{array}{l}4.29 \mathrm{~g} / \mathrm{L} \\
\text { heptakis(6-tri-O- } \\
\text { methyl)- } \beta-\mathrm{CD}\end{array}$} & \multicolumn{2}{|c|}{$\begin{array}{l}1.85 \mathrm{~g} / \mathrm{L} \\
\text { heptakis(6-O-sulfo)- } \\
\beta-\mathrm{CD}\end{array}$} \\
\hline $4 / 9$ & 1 & 0 & 1.61 & 5.19 & 1.67 & 10.63 & 2.64 & 21.38 & 1.30 & 5.22 \\
\hline $6 / 12$ & 1 & 0 & $* 1.02$ & 0.41 & 1.24 & 3.16 & $* 1.14$ & 2.36 & 1.20 & 4.63 \\
\hline $6 / 13$ & 1 & 0 & 1.04 & 0.83 & 1.71 & 8.48 & 1.51 & 8.84 & 1.04 & 1.08 \\
\hline $8 / 9$ & $* 1.10$ & 2.41 & 1 & 0 & 1.12 & 1.43 & 1.51 & 8.84 & 1.04 & 1.13 \\
\hline $10 / 11$ & 1.10 & 2.69 & 1 & 0 & 1 & 0 & 1.03 & 0.71 & 1.12 & 3.65 \\
\hline $13 / 17$ & 1.22 & 2.73 & 1 & 0 & $* 1.24$ & 3.19 & $* 1.40$ & 4.72 & 1.29 & 6.57 \\
\hline $14 / 25$ & 1.23 & 4.45 & 1 & 0 & 1 & 0 & $* 1.01$ & 0.49 & $* 1.54$ & 7.25 \\
\hline $17 / 5$ & 1 & 0 & 1.26 & 4.34 & 1 & 0 & 1 & 0 & 1.34 & 8.67 \\
\hline $18 / 25$ & 1 & 0 & $* 1.26$ & 2.20 & $* 1.23$ & 1.92 & $* 1.28$ & 3.61 & 1.23 & 5.00 \\
\hline $19 / 18$ & 1 & 0 & 1.05 & 0.83 & 1.05 & 0.97 & 1.05 & 1.05 & 1 & 0 \\
\hline $19 / 25$ & 1 & 0 & $* 1.20$ & 1.91 & $* 1.17$ & 1.61 & $* 1.22$ & 3.34 & $* 1.23$ & 5.00 \\
\hline $20 / 14$ & 1 & 0 & 1.11 & 1.12 & 1.14 & 1.34 & 1.12 & 2.86 & 1.60 & 7.55 \\
\hline
\end{tabular}

* - reversed migration order of the $i, j$ compounds in critical pair 


\section{Table 3.}

2 Correlation coefficients, $R^{2}$, between the LC retention times and the MEKC migration times of flavones, related compounds and phenolic acids.

3 For LC separation conditions see the references [26,29,32,49]; MEKC conditions as in Figure 3B. 4

\begin{tabular}{|c|c|c|c|c|c|c|c|c|c|}
\hline \multirow{2}{*}{\multicolumn{2}{|c|}{ LC column }} & \multirow{2}{*}{ LC mobile phase } & \multicolumn{3}{|c|}{ Without CD } & \multicolumn{3}{|c|}{$\begin{array}{l}1.85 \mathrm{~g} / \mathrm{L} \text { heptakis-(6-O-sulfo)- } \beta \text { - } \\
\mathrm{CD}\end{array}$} & \multirow[t]{2}{*}{$\begin{array}{l}\text { LC } \\
\text { conditions }\end{array}$} \\
\hline & & & Flavones & $\begin{array}{l}\text { Phenolic } \\
\text { acids }\end{array}$ & $\begin{array}{l}\text { All } \\
\text { compounds }\end{array}$ & Flavones & $\begin{array}{l}\text { Phenolic } \\
\text { acids }\end{array}$ & $\begin{array}{l}\text { All } \\
\text { compounds }\end{array}$ & \\
\hline 1 & $\begin{array}{l}\text { Ascentis Express C18, } \\
\text { (Supelco, Bellefonte, PA, USA), } \\
30 \times 3 \mathrm{~mm}, 3 \mu \mathrm{m}\end{array}$ & $\begin{array}{l}15 \%(\mathrm{v} / \mathrm{v}) \mathrm{ACN} / \\
\text { water, } \\
0.5 \mathrm{ml} / \mathrm{min}, 40^{\circ} \mathrm{C}\end{array}$ & 0.564 & 0.232 & 0.196 & 0.425 & 0.188 & 0.189 & {$[26,32]$} \\
\hline 3 & $\begin{array}{l}\text { Novapak Phenyl, } \\
\text { (Waters, Milford, MA, USA), } 50 \\
\text { x } 3.9 \mathrm{~mm}, 5 \mu \mathrm{m}\end{array}$ & $\begin{array}{l}15 \%(\mathrm{v} / \mathrm{v}) \mathrm{ACN} / \\
\text { water, } \\
1 \mathrm{ml} / \mathrm{min}, 40^{\circ} \mathrm{C} \\
\end{array}$ & 0.417 & 0.002 & 0.155 & 0.332 & 0.001 & 0.140 & {$[29,49]$} \\
\hline 4 & $\begin{array}{l}\text { Purospher STAR, } \\
\text { (Merck, Darmstadt, Germany), } \\
125 \times 4 \mathrm{~mm}, 5 \mu \mathrm{m}\end{array}$ & $\begin{array}{l}30 \%(\mathrm{v} / \mathrm{v}) \mathrm{ACN} / \\
\text { water, } \\
1 \mathrm{ml} / \mathrm{min}, 40^{\circ} \mathrm{C}\end{array}$ & 0.506 & 0.045 & 0.200 & 0.480 & 0.034 & 0.178 & [49] \\
\hline
\end{tabular}
5 


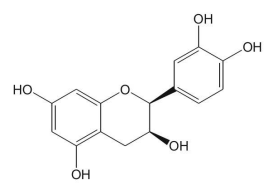

1 (-)-Epicatechin

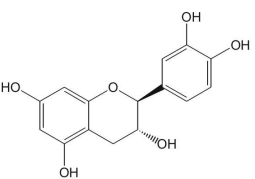

2 (+)-Catechin

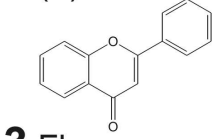

3 Flavone

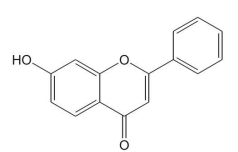

4 7-Hydroxyflavone
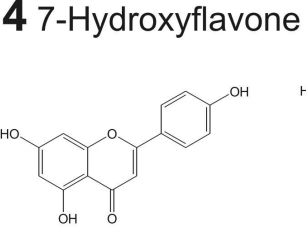

5 Apigenin

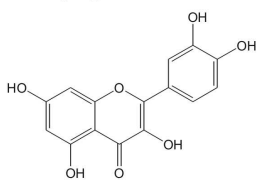

6 Quercetin

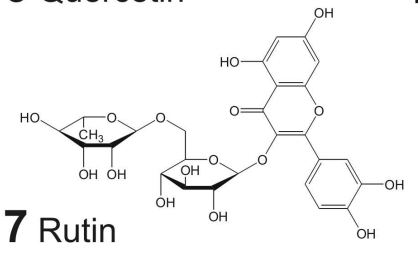

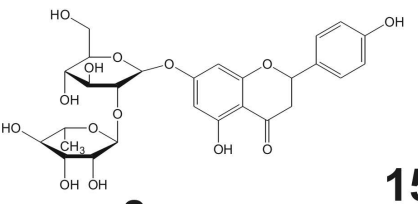

8 Naringin

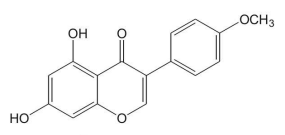

9 Biochanin A

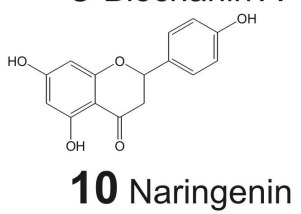

10 Naringenin

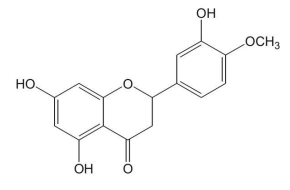

11 Hesperetin

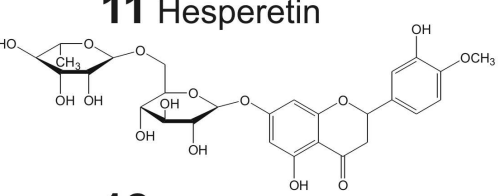

12 Hesperidin

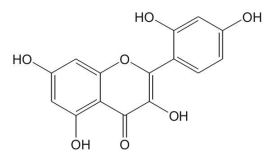

13 Morin

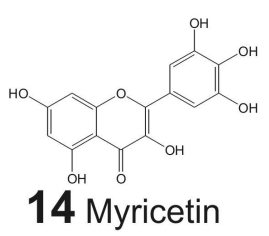

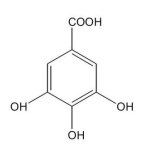

15 Gallic acid<smiles>O=C(O)c1ccc(O)c(O)c1</smiles>

16 Protocatechuic 23 p-Coumaric acid

17 p-Hydroxybenzoic acid

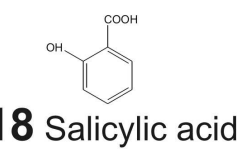

18 Salicylic acid

24 Ferulic acid

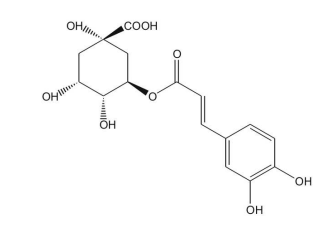

25 Chlorogenic acid

22 Caffeic acid

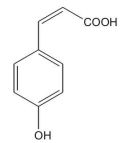

acid

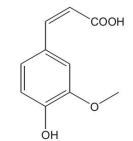

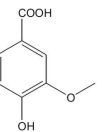

19 Vanilic acid

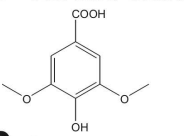

20 Syringic acid

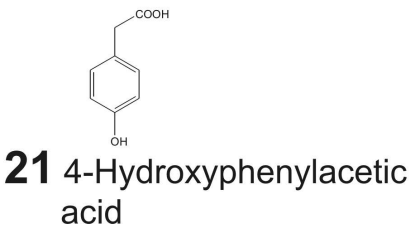

$231 \times 291 \mathrm{~mm}(300 \times 300 \mathrm{DPI})$ 
A
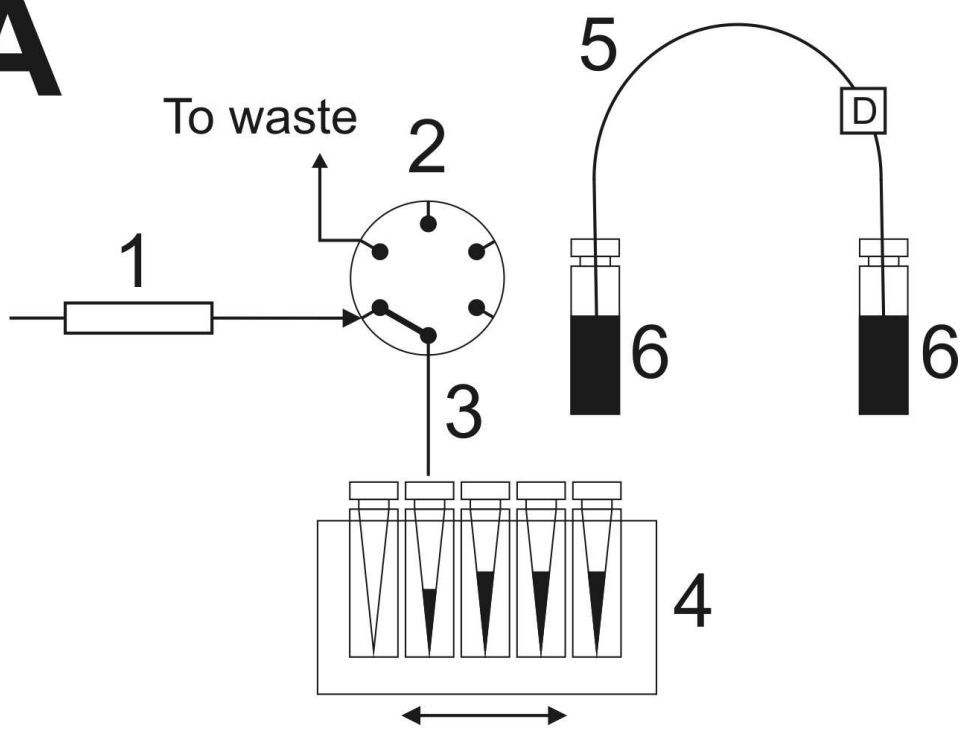

B

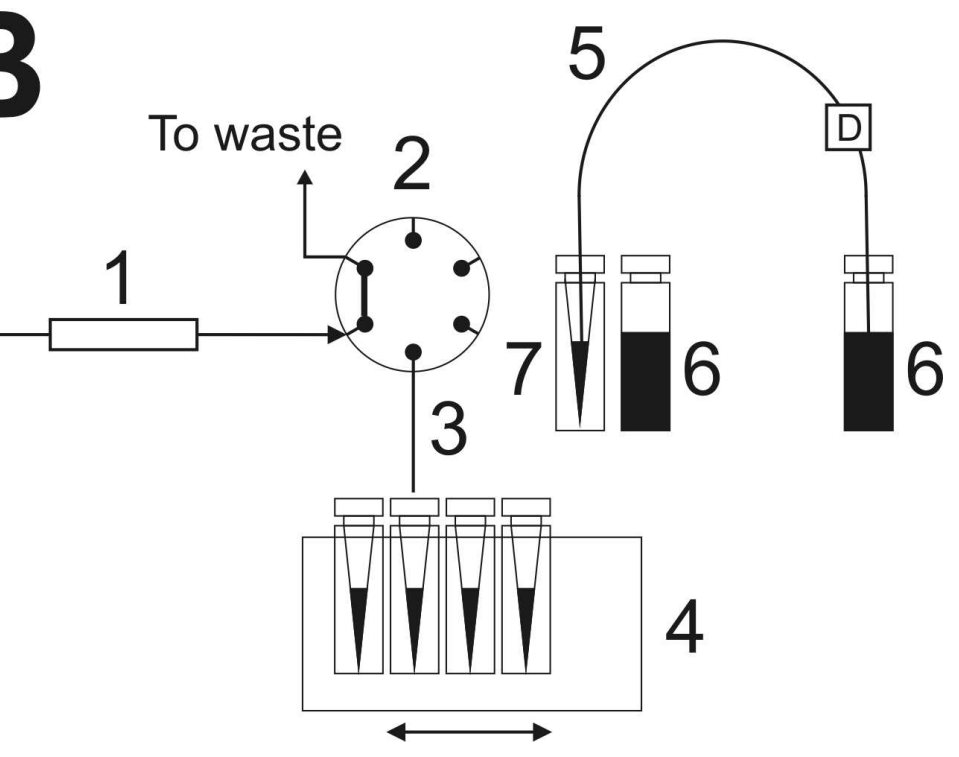

$114 \times 177 \mathrm{~mm}(300 \times 300$ DPI $)$ 

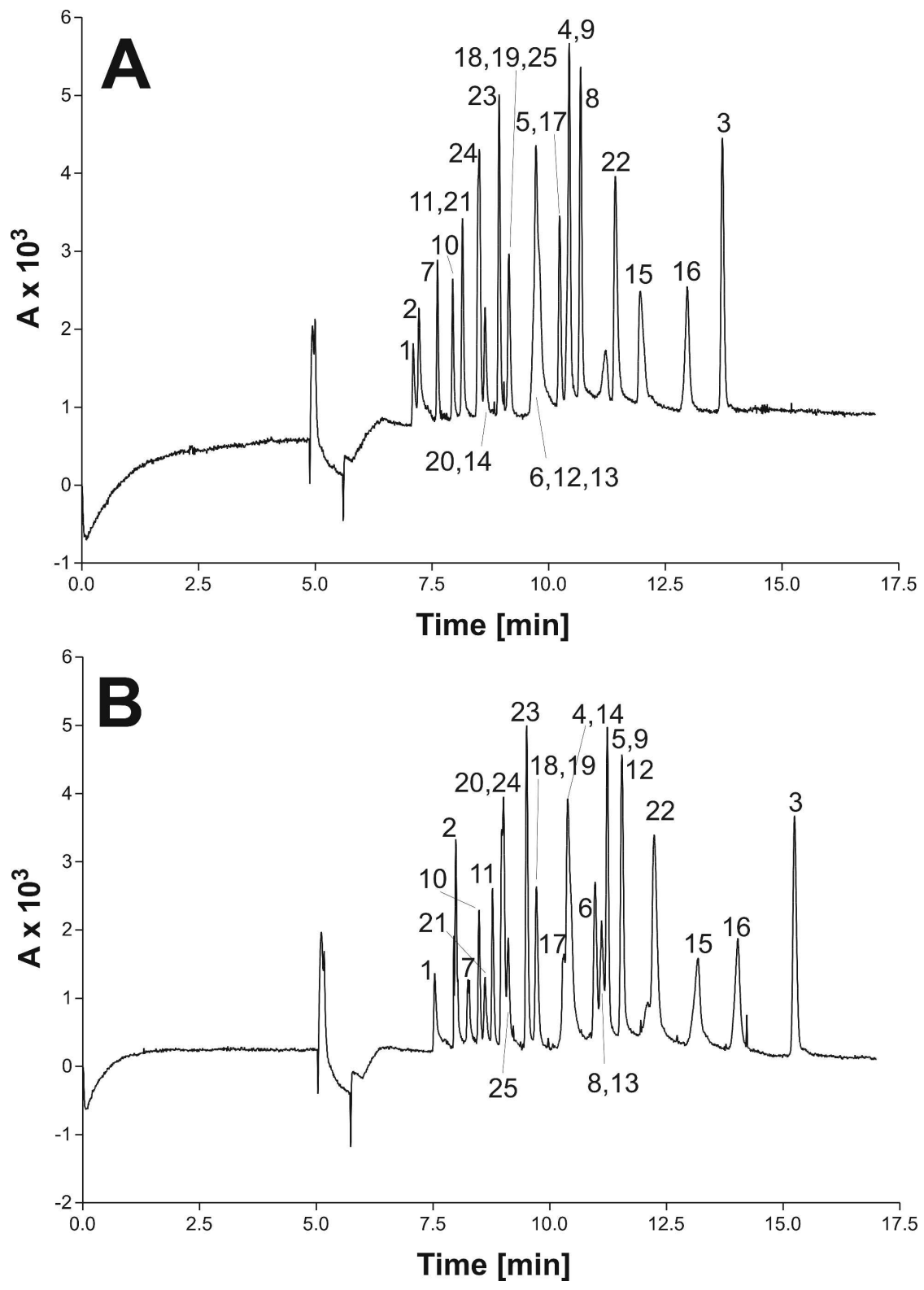

$166 \times 232 \mathrm{~mm}(600 \times 600 \mathrm{DPI})$ 


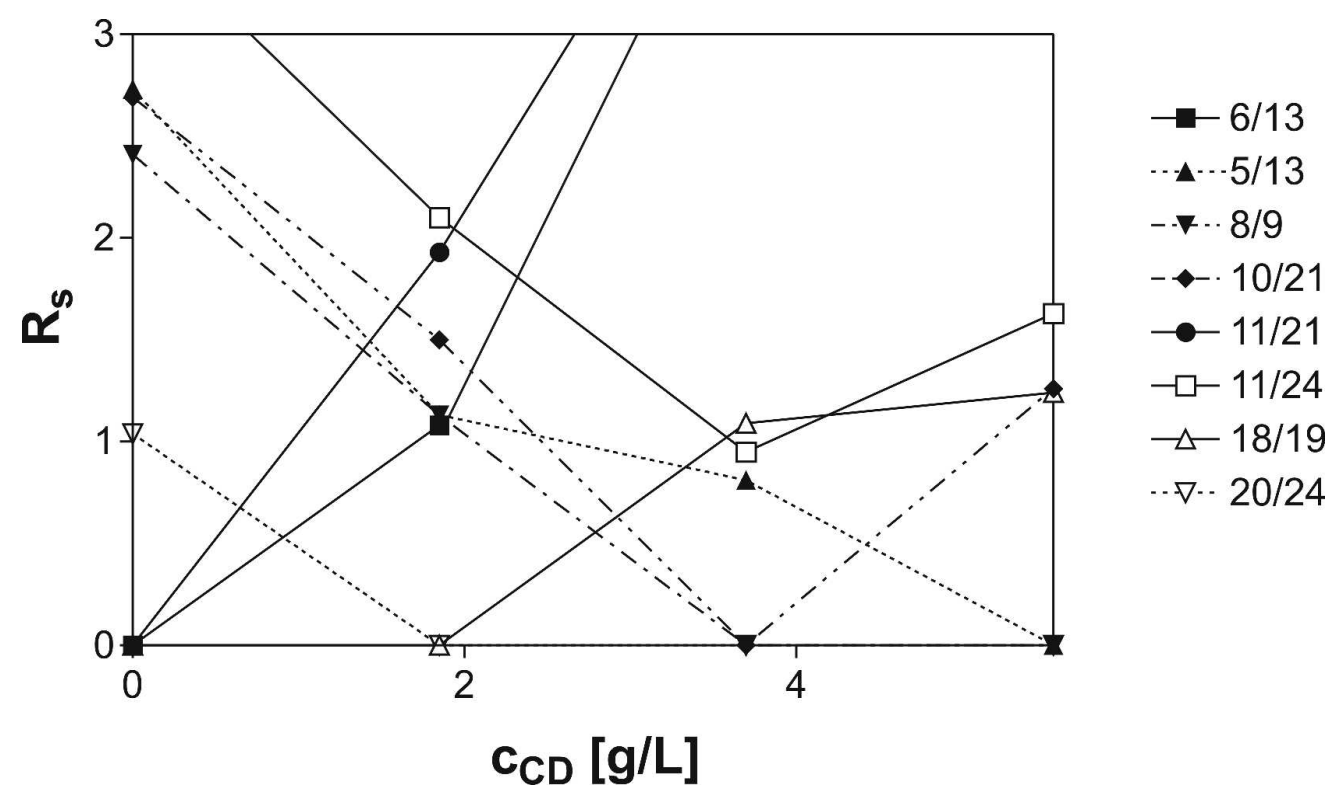

$141 \times 83 \mathrm{~mm}(600 \times 600$ DPI $)$ 


\section{$x$}




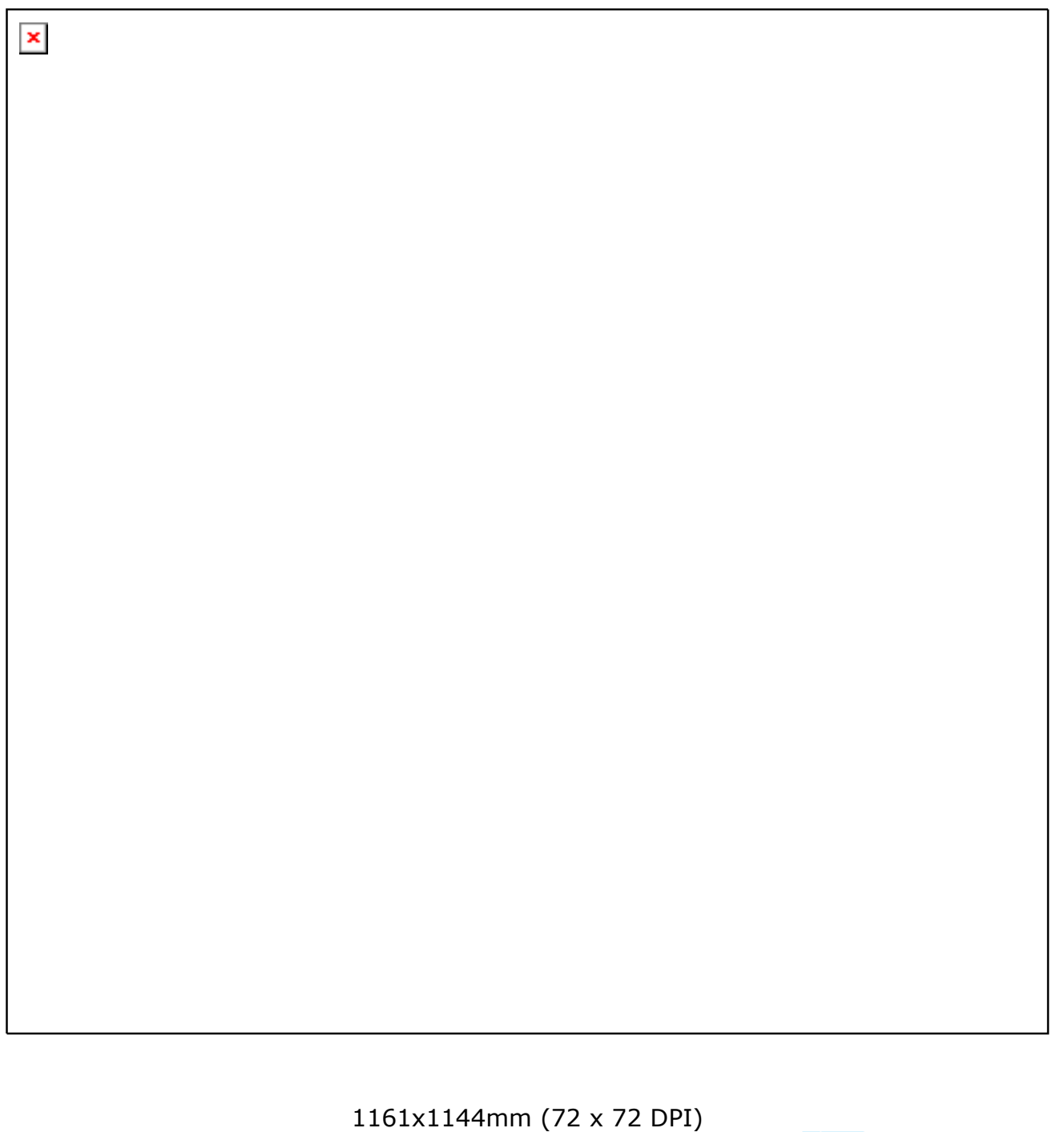

1

2

3

4

5

6

7

8

9

10

11

12

14

15

16

17

18

19

20

22

23

24

25

26

27

29

30

31

32

33

34

35

36

37

42

43

44

45

46

47

48

49

50

51

52

53

54

55

56

57

58

59

60 